\title{
Managing the Future Forest Resource through Designer Trees
}

\author{
CL Todoroki ${ }^{1} \&$ SD Carson ${ }^{2}$ \\ ${ }^{1}$ Forest Research, Sala St, Rotorua, New Zealand \\ Email: christine.todoroki@,forestresearch.co.nz \\ ${ }^{2}$ Carson Associates Ltd, 82 Tihi Rd, Rotorua, New Zealand \\ Email: sue.carson@,forest-genetics.com
}

\begin{abstract}
With today's tree improvement technology coupled with knowledge of the influence of site, silvicultural and other forest management practices on tree growth and log quality, it is possible to manipulate tree form to engineer designer trees with specific characteristics. Theoretically, at least, we have the ability to create stands and portfolios of forests to optimise suitability for different end uses. We could design Structural Forests to optimise the quality of lumber for building materials, for furniture and mouldings markets (Long Clear Forests), for fingerjoint markets (Short Clears Forests) or for pulp and paper industries (PulpWood Forests).
\end{abstract}

This begs a question: "Can we significantly increase product value by targeting forest management and tree improvement goals to a specific end-product?"

The goal of this project is to examine methods for exploring the value of the final end-product resulting from manipulating tree characteristics through forest management and tree improvement. This will be done by extending the forest resource forward to the wood product, and providing linkage back to forest management and genetic selection of parent stock, whether it be seed, clones, or specific genes.

In this paper effort is concentrated on exploring the impact of manipulating tree characteristics on the value of LongClears Forests. We attempt to identify those important tree and branching characteristics that could be manipulated to optimise production of specific lumber products. The range within which the relevant characteristics can be manipulated by silviculture and genetics is defined and the impact that this range has on the lumber suitable for mouldings, furniture, joinery, and remanufacturing markets is quantified.

Quantification of the impact of targeting management and breeding of trees to specific end-uses is achieved through a methodological approach whereby we model a range of logs with different characteristics and use a combination of mathematical programming and operations research techniques including Data Envelopment Analysis to calculate targeted product outturn. 


\section{Introduction}

Tree breeding research has identified a number of traits, such as growth rate, straightness, branch habit, wood properties, and dothistoma resistance, that can be genetically controlled (Burdon 1992). This provides an opportunity for creating "designer trees" to produce specific products (Carson 1996). A number of breeding improvement programmes have been developed but, as they were developed to benefit the forest grower, until recently they have largely focussed on the growing of logs rather than on end-products (Shelbourne et al. 1997). Furthermore, results derived from fast growth crops have indicated that the increase in recoverable volume is accompanied by a decrease in product quality. This has caused a shift in emphasis from improvement for the forest-grower to improving end-product value.

Since genetic selection involves trade-offs in gain when selection is for more than one characteristic, the question of how much emphasis to attach to each trait becomes important in order to maximise profitability from tree improvement. While comprehensive lists of selection criteria related to breeding-objective traits for a range of end products have been developed, the ability to predict or quantify relative economic values of the traits, and hence aggregate genotypes, remains somewhat elusive.

Methodology developed for animal breeding (Hazel 1943, Goddard 1998) is thought by many to be the most appropriate approach, and has been directly applied to tree breeding (Borralho et al. 1993, Chambers 1999, Greaves et al. 1997). This method uses a model that is a linear combination of traits in which the coefficient of each trait is its effect on profit when all other traits are held constant (Hazel 1943). The method necessitates (in practice) that when the profitability of genotypes is compared, each should be evaluated with the management variables set to their optimum value for that genotype (Goddard 1998). We suggest that this approach is too constrained to accurately model profitability for the range of options available to the forest manager charged with managing a specific forest because this model severely restricts the flexibility to take account of the impact of site and silviculture. We suggest that forest management models, many of which have been extensively used and tested, can be used more productively to more directly model profitability to take into account the interaction of site quality, silvicultural regime, and wood processing processes. It is very important to do this because non-genetic influences most often have a very large impact on the final product compared to differences among trees arising from genetic selection.

In the work presented here we consider an alternative approach utilising an existing model, AUTOSAW, which simulates product out-turn from sawing logs according to different sawing patterns and evaluates the efficiency of sawing and predicts the volume of different grades of timber, and a new approach, Data Envelopment Analysis (DEA), that can be used to quantify 
profitability. Rather than attempting to quantify the amount by which net profit may be expected to increase for each trait with all others held constant, we focus on target products and use existing forest management and sawing models to work backwards through log definition to tree description, thus creating a "designer tree" which will maximise profit. After working backwards from the mature tree, one would then consider the forest growing requirements, management practices, and genetic selection strategies that would achieve this "designer tree". This would give us the ability to create stands and portfolios of forests to optimise suitability for different end uses such as Structural Forests to optimise the quality of lumber for building materials, LongClears Forests for mouldings and furniture markets, ShortClears Forests for fingerjoint markets and PulpWood Forests for the pulp and paper industries.

\section{Research Tools}

\section{AUTOSAW}

One of the tools that we have available for definition and description of target products at an individual piece level is AUTOSAW, a log sawing simulation system (Todoroki 1990). AUTOSAW is a sawing simulator that provides graphic visualisation of three-dimensional "glass" log models. The models can assume both irregular and eccentric forms and incorporate branches at any orientation, and differing branch morphologies (Todoroki 1997a). Within AUTOSAW the virtual logs and their internal branching structures can be viewed at any rotational setting and at any stage of the sawing process starting from the unsawn "glass" log through to individual boards with knot, pith, and wane defects on the four sawn surfaces.

In the past all virtual logs were constructed from detailed three-dimensional external and internal measurements of actual logs (Park and Leman 1983, Somerville 1985) with branches individually located, measured, and mapped. More recently a branch model, BLOSSIM (Grace et al. 1999) that predicts the number and location of branch clusters, as well as the number, size and spatial arrangement of individual branches, has been used to generate branch data compatible with that required by the AUTOSAW system (Pont et al. 1999). In 1997 growth ring models were introduced to the system and these have paved the way for inclusion of important wood properties such as wood density, spiral grain, and tracheid length through linkage with wood property models (Tian and Cown 1997). This allows, for example, provision of a density distribution along a board, in addition to identification of the location, size and type of knots within each board.

Sawn lumber products and residues can be obtained using AUTOSAW through rigorous mathematical process modelling using optimization techniques, heuristics, and meta-heuristics (Todoroki 1997b). 
The aim of log sawing simulation is to replicate sawmill sawing practices and patterns, and the aim for sawing optimisation to extract the maximum value of lumber from each log (subject to constraints on sawmill plant and sawing practices). To achieve operational efficiency at a sawmill a piece by piece analysis of material through the mill is required. Although AUTOSAW was not originally designed to model operational efficiency, material flows and machine bottlenecks can be predicted through knowledge of sawpatterns, sawmill equipment, individual piece counts at machine centres and machine cycle times. In the work presented here AUTOSAW will be also used in this capacity.

\section{Data Envelopment Analysis}

Tools that provide linkage and analysis of target products to log and tree definition include operations research techniques such as data envelopment analysis, DEA, and statistical tools including regression analysis. While most readers will be familiar with statistical techniques, DEA is not quite as well known. DEA is a tool that is becoming increasingly used to evaluate and measure the performance of manufacturing and service operations. While DEA has had extensive use in the health and education sectors, application in the forestry and forest products sector is relatively new. Kao (1998) provides an example where DEA is used to measure the efficiency of forest districts in Taiwan, and Fotiou (2000) uses DEA to estimate the efficiency of sawmills in Greece. A model that extends the standard DEA model developed by Charnes et al. (1978) to account for undesirable outputs when measuring ecological efficiency was presented by Dyckhoff and Allen (2001).

With DEA relative performance measurements of units known as Decision Making Units, DMUs, are derived from inputs and outputs, and in the simplest form, work on the premise that more output and less input yield a higher degree of efficiency. While these inputs and outputs are regarded as "goods", undesirable outputs such as waste, pollutants, and emissions are regarded as "bads" and are treated as such.

Consider a problem with $n$ DMUs, each with $m$ inputs and $s$ outputs. The efficiency of each DMU, $i$, is defined as:

$$
\text { Efficiency }=\frac{\text { weighted sum of outputs }}{\text { weighted sum of inputs }}=\frac{\sum_{k=1}^{s} v_{k} y_{k i}}{\sum_{j=1}^{m} u_{j} x_{j i}}
$$

where $\quad y_{k i}=$ amount of output $k$ produced by DMU $i$

$x_{j i}=$ amount of input $j$ used by DMU $i$

$v_{k}=$ weight assigned to output $k$

$u_{j}=$ weight assigned to input $j$ 
While the amount of inputs and outputs, $x_{j i}$ and $y_{k i}$ respectively, are known a priori, weights $v_{k}$ and $u_{j}$ must be determined. Charnes et al. proposed that each unit should be assigned a set of weights that shows it in the most favourable light in comparison to all other units. The weights and the relative efficiency of each DMU are found by solving the following fractional programming problem that constrains relative efficiency to the range $[0,1]$ :

$$
\begin{array}{ll}
\text { Maximize } & \frac{\sum_{k=1}^{s} v_{k} y_{k p}}{\sum_{j=1}^{m} u_{j} x_{j p}} \\
\text { subject to } & \frac{\sum_{k=1}^{s} v_{k} y_{k i}}{\sum_{j=1}^{m} u_{j} x_{j i}} \leq 1 \quad \forall i \\
& v_{k}, u_{j} \geq 0 \quad \forall k, j
\end{array}
$$

The fractional problem can be reformulated as a linear problem and solved, $p$ times (once for each DMU) using an LP solver or specialisied DEA software.

\section{Designing Trees for the LongClears Forest Portfolio}

To explore the potential of combinations of these tools for development of designer trees a case study representing development of a LongClears Forest Portfolio is presented. The objective of the LongClears Forest is to produce long sections of defect-free lumber. This lumber is suitable for use in the mouldings, furniture, joinery, and remanufacturing markets. Defect-free lumber may be produced naturally through long internode breeds or artificially through pruning whereby branches are removed (earlier than they are naturally shed) from the juvenile tree to enable the formation of knot-free wood. It is this latter option, pruning, that we will choose in the design for an optimal butt log for our designer tree.

In the work presented here we will design a stem which has the highest efficiency for production of long clears. For the purposes of this case study we define "long lumber" as extending from $1.8 \mathrm{~m}$ to the full log length in the pruned butt log.

There are two key variables that significantly influence the recovery of clearwood from pruned logs: small-end diameter (SED) and the size of the pruned defect core (DC). Other variables that have a lesser yet still significant effect include taper and sweep. In defining the pruned butt log our aim is to quantify these variables. To achieve this we take the perspective of a solid wood 
processor wanting to produce as much of this valuable product as possible whilst also concerned with efficiency in processing.

A combined approach that linked log sawing optimisation and sawmill simulation through data envelopment analysis, DEA, was developed. The method used an extended DEA model to derive an efficiency measure for pruned logs. The efficiency measure was used in conjunction with a measure for profitability to quantify characteristics of the pruned butt log best suited for the LongClear Forest Portfolio.

\section{Efficiency}

The Pruned Log DEA model had one input that reflected processing time at the bottleneck machine centre. It was based on individual piece counts at each machine centre and cycle times. Three outputs were used to account for all products arising from breakdown of each log:

1) clearwood yield, $y_{1 i}$, representing the volume of all clear lumber $1.8 \mathrm{~m}$ and longer, that was extracted from each pruned log, $\mathrm{i}$

2) remaining lumber yield, $y_{2 i}$, representing the total volume of all lumber and excluding clearwood as defined above

3) residues, $y_{3 i}$.

Residues were treated as "bad" outputs, that is as pollutants as in Dyckhoff and Allen (2001). To deal with the undesirable output a linear transformation was applied as follows:

Let $r_{i}$ be the amount of residues (sawdust and chips) produced by $\mathrm{DMU}_{i}\left(\log _{i}\right)$ and let $R$ be the maximum amount of residues produced. I.e. $R=\operatorname{Max}_{i}\left\{r_{i}\right\}$

Then the transformation for the third output, $y_{3 i}$, is given by:

$$
y_{3 i}=R-r_{i} \quad \forall i
$$

\section{$\underline{\text { Pruned Log DEA Model }}$}

$$
\begin{array}{ll}
\text { Maximize } & \frac{\sum_{k=1}^{3} v_{k} y_{k p}}{u x_{p}} \\
\text { subject to } & \frac{\sum_{k=1}^{3} v_{k} y_{k i}}{u x_{i}} \leq 1 \quad \forall i \\
& v_{k}, u \geq 0 \quad \forall k
\end{array}
$$


where $\quad y_{1 i}=$ amount of clearwood produced by $\log i$

$y_{2 i}=$ amount of other lumber yield produced by $\log i$

$y_{3 i}=$ transformed amount of residues produced by $\log i$

$x_{i}=$ processing time used by $\log i$

$v_{k}=$ weight assigned to output $k ; k \in 1 . .3$

$u=$ weight assigned to the sole input, processing time

As mentioned earlier, in this approach weights were found by solving the fractional programming problem, rather than being assigned a priori. This allowed each DMU (log) to be seen in its most favourable light in comparison to all other units.

In all, there were 382 DMUs each representing a pruned pinus radiata butt log. Log data was derived from pruned log assessments made at 19 sites throughout New Zealand (Figure 1) from unimproved stock. The logs varied considerably in age (16 to 42 years), size (SED from 27 to 58 $\mathrm{cm}$ ), and pruning quality (DC from 17 to $42 \mathrm{~cm}$ ). Pruning had been carried out in one, two, or three lifts representing 1, 29, and $70 \%$ of the sample respectively. As logs were selected on the basis of being either sawlogs or peeler bolts they were relatively straight in terms of New Zealand log grading standards and had sweep ranging from 1.2 to $22.3 \mathrm{~mm} / \mathrm{m}$, with $81 \%$ having sweep less than $10 \mathrm{~mm} / \mathrm{m}$ and $97 \%$ with sweep less than $15 \mathrm{~mm} / \mathrm{m}$. Statistics summarising the $\log$ sample are provided in Table 1.

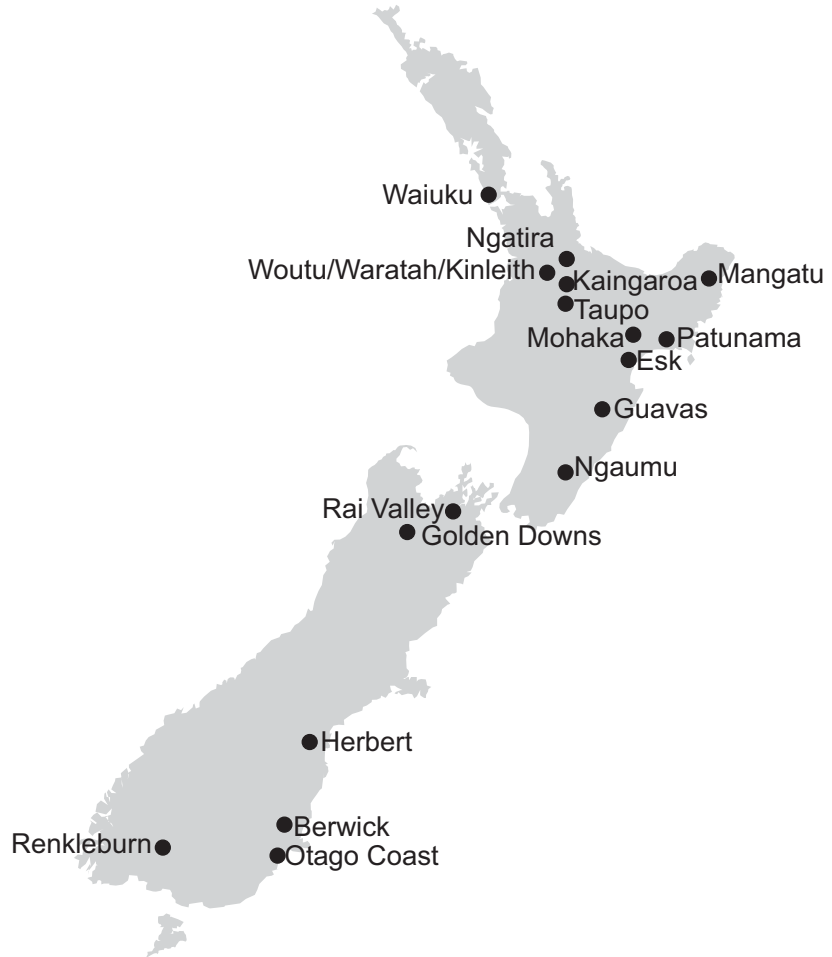

Figure 1: Locations from which modelled logs were derived 


\begin{tabular}{lcccc}
\hline \multicolumn{1}{c}{ Characteristic } & Minimum & Maximum & Average & $\begin{array}{c}\text { Standard } \\
\text { deviation }\end{array}$ \\
\hline Age (years) & 16 & 42 & 27 & 5 \\
SED $(\mathrm{cm})$ & 27 & 58 & 40 & 6 \\
Taper $(\mathrm{mm} / \mathrm{m})$ & 0.9 & 27.8 & 10.7 & 4.4 \\
Sweep $(\mathrm{mm} / \mathrm{m})$ & 1.2 & 22.3 & 7.2 & 3.4 \\
Length $(\mathrm{m})$ & 4.5 & 5.5 & 5.2 & 0.2 \\
Defect core $(\mathrm{cm})$ & 17 & 42 & 27 & 4 \\
Clearwood sheath $(\mathrm{cm})$ & 1 & 33 & 12 & 5 \\
PLI tenth-mm & 0.5 & 11.9 & 4.4 & 1.7 \\
\hline
\end{tabular}

Table 1: Statistics of key characteristics of the 382-log sample

Virtual logs constructed from the log data were "sawn" in a sawing simulator and log products and processing times recorded for each log. Log products served as output variables to the DEA model and were determined using log sawing optimisation by a dynamic programming quadratic fit method, DPQF (Todoroki 1997b) for primary log breakdown and a DP approach with grade maximisation (Todoroki and Rönnqvist 1997) for subsequent processing. The sole input to the DEA model, $x_{i}$, the processing time required to complete log breakdown, consisted of the time required to load the log on the carriage, turn, return, and release the log, and the time required by the bottleneck machine center. The bottleneck machine, ie that requiring the maximum processing time, was determined on a log by log basis through individual piece counts and machine cycle times.

The fractional problem was reformulated as a linear problem and solved for each of the 382 pruned logs using a customised version of XLP (Oishi 1998). This defined an efficiency measure for each log.

\section{Profitability}

Another performance measure, profitability, was also calculated for each log. Profitability was defined as the ratio of lumber value to log cost. Lumber was priced according to grade and dimensions and total lumber value tabled for each log. Log costs were based on the pruned log price of NZ\$205 per cubic meter using the Japanese Agricultural Standard (JAS) for log volume calculations as described in the report by Ellis et al. 1996. 


\section{Results}

Efficiency scores plotted against profitability scores are shown in Figure 2. The plot is divided into four main quadrants, with the division occurring about the average efficiency and profitability scores. Naming of the quadrants follows that used by Boussofiane et al. (1991) with the north-west quadrant labelled "Sleeper", the south-west labelled "?", the south-east labelled "Dog" and the north-east labelled "Star". "Sleeper" logs are represented by below-average efficiency and high profitability, "?" below-average in both efficiency and profitability, "Dogs" have high efficiency but low profitability, and "Stars" the most efficient and profitable logs. A further subdivison within the "Star" quadrant denotes those logs that have above-average efficiency and profitability within that quadrant. Denoted by "Super-star", this corner contained 10 logs.

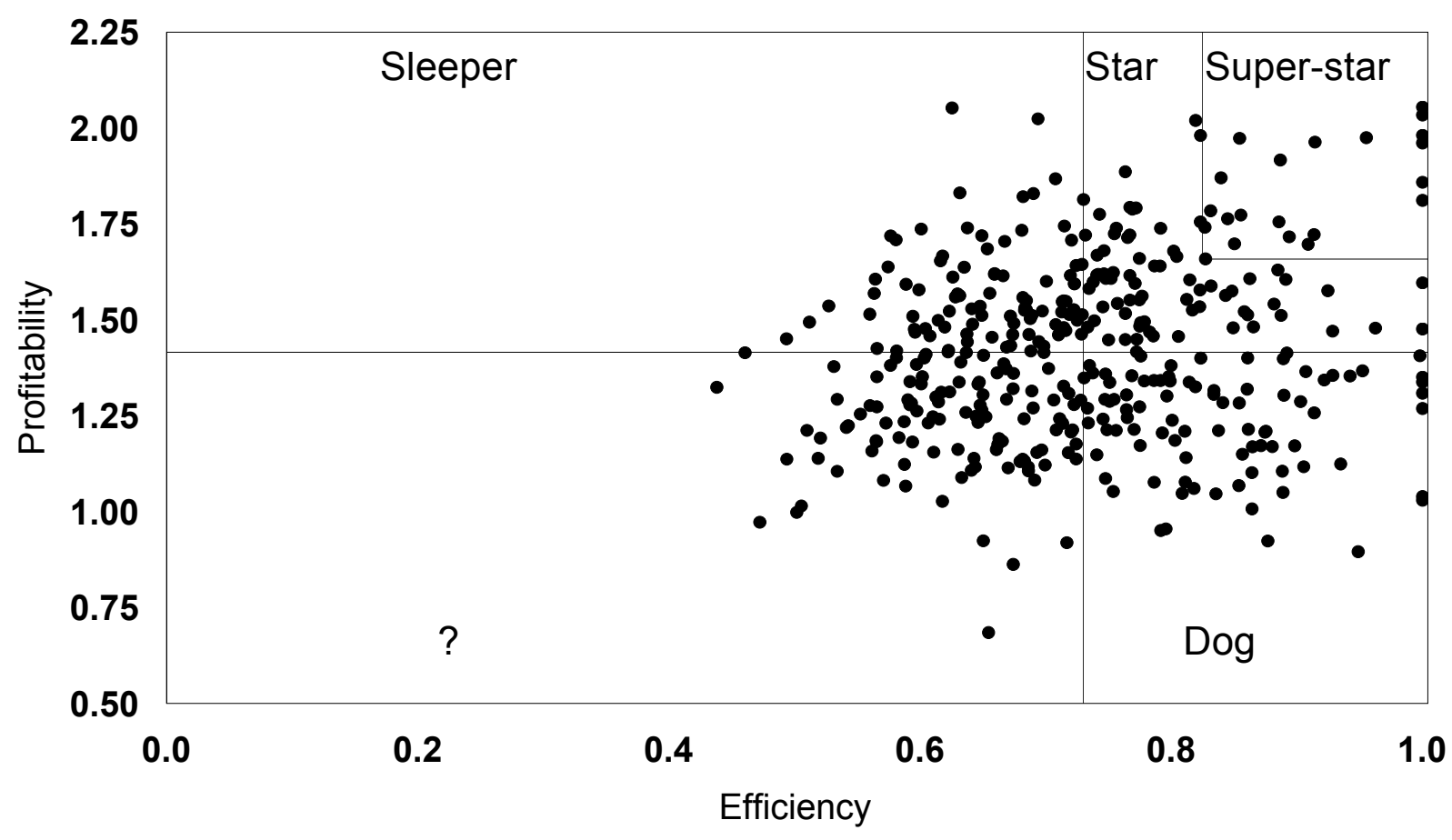

Figure 2: Efficiency-profitability matrix for the 382-log sample

Correlation coefficients relating log and processing variables with efficiency and profitability are shown in Table 2. The main points are noted below.

Of the log characteristics, sweep showed the highest correlation with efficiency, and was negatively correlated. Thus the greater the sweep, the lower the efficiency. The greatest correlation with efficiency was obtained with the processing time variable. This was not unexpected as processing time was selected as a key input in efficiency assessment. Central log volume (CVOL) and pruned log index (PLI) also showed some small positive correlation with efficiency and both showed strong correlation with profitability. 
The highest correlation with profitability was derived from the relationship with clearwood yield with a correlation coefficient of 0.82 . As clearwood value was a contributing factor to the profitability score, this relationship was not unexpected. PLI and clearwood sheath (SED-DC) also demonstrated strong relationships with coefficients of 0.77 and 0.72 respectively. Total lumber volume, central log volume (CVOL), and total log volume (LVOL) had coefficients of $0.71,0.70$, and 0.68 respectively. The two measures of $\log$ form, SED and taper, showed a positive correlation with profitability while sweep demonstrated a negative correlation.

\begin{tabular}{|c|c|c|}
\hline Variable & Efficiency & Profitability \\
\hline \multicolumn{3}{|c|}{ Log Form and Quality } \\
\hline Small End Diameter, SED & .18 & .57 \\
\hline Taper & -.20 & .50 \\
\hline Sweep & -.43 & -.25 \\
\hline Defect Core, DC & -.02 & -.12 \\
\hline Clearwood sheath, SED - DC & .21 & .72 \\
\hline Pruned log index, PLI & .30 & .77 \\
\hline Total log volume, LVOL & .16 & .68 \\
\hline Central log volume, CVOL & .30 & .70 \\
\hline \multicolumn{3}{|c|}{ Log products } \\
\hline Clearwood & .18 & .82 \\
\hline Total lumber & .23 & .71 \\
\hline Residues & .07 & .10 \\
\hline \multicolumn{3}{|c|}{ Processing } \\
\hline Bottleneck processing time & -.53 & .36 \\
\hline
\end{tabular}

Table 2: Correlation coefficients linking performance measures to log and processing variables

Average log and processing variables in each of the quadrants are summarised in Table 3. Average characteristics of logs in the "Super star" corner are also shown.

Results suggest that log sweep had the greatest influence on efficiency. Overall, the most efficient and profitable logs were large (SED $43 \mathrm{~cm})$, had a large clearwood sheath $(16 \mathrm{~cm})$, minimal sweep $(6 \mathrm{~mm} / \mathrm{m})$ and moderate taper $(12 \mathrm{~mm} / \mathrm{m})$. The top performers, the Super-stars, were larger still (SED $50 \mathrm{~cm}$, clearwood sheath $22 \mathrm{~cm}$ ) with minimal sweep and moderate taper. 


\begin{tabular}{|c|c|c|c|c|c|}
\hline & $\begin{array}{c}\text { “?" } \\
\text { Quadrant 1 }\end{array}$ & $\begin{array}{c}\text { "Sleeper" } \\
\text { Quadrant } 2 \\
\end{array}$ & $\begin{array}{c}\text { "Dog" } \\
\text { Quadrant } 3 \\
\end{array}$ & $\begin{array}{c}\text { "Star" } \\
\text { Quadrant } 4 \\
\end{array}$ & $\begin{array}{l}\text { "Super-stars" } \\
\text { NNE Corner }\end{array}$ \\
\hline $\mathrm{SED}(\mathrm{cm})$ & $37^{(2,4)}$ & $41 *$ & $37^{(2,4)}$ & $43 *$ & $50 *$ \\
\hline Taper $(\mathrm{mm} / \mathrm{m})$ & $9.8^{*}$ & $13.5^{*}$ & $7.8^{*}$ & $11.6^{*}$ & $14.5^{(1,3)}$ \\
\hline Sweep $(\mathrm{mm} / \mathrm{m})$ & $9.2 *$ & $7.3^{(1,4)}$ & $6.4^{(1)}$ & $5.7^{(1,2)}$ & $4.9^{(1,2)}$ \\
\hline Defect core, DC (cm) & 28 & 27 & 28 & 27 & 28 \\
\hline Clearwood sheath $(\mathrm{cm})$ & $9^{(2,4)}$ & $14 *$ & $10^{(2,4)}$ & $16^{*}$ & $22 *$ \\
\hline Log Volume $\left(\mathrm{m}^{3}\right)$ & $0.66^{(2,4)}$ & $0.83^{*}$ & $0.65^{(2,4)}$ & $0.92 *$ & $1.26^{*}$ \\
\hline LongClears Volume $\left(\mathrm{m}^{3}\right)$ & $0.11^{(2,4)}$ & $0.22 *$ & $0.10^{(2,4)}$ & $0.28^{*}$ & $0.49 *$ \\
\hline Total lumber $\left(\mathrm{m}^{3}\right)$ & $0.40^{(2,4)}$ & $0.53 *$ & $0.41^{(2,4)}$ & $0.62 *$ & $0.88^{*}$ \\
\hline Residues $\left(\mathrm{m}^{3}\right)$ & $0.26^{*}$ & $0.30^{(1,3)}$ & $0.24^{*}$ & $0.31^{(1,3)}$ & $0.38^{(1,3)}$ \\
\hline Processing time (s) & $82^{(2,3)}$ & $87^{*}$ & $65^{*}$ & $79^{(2,3)}$ & $89^{(3)}$ \\
\hline Efficiency & $0.63^{*}$ & $0.66^{*}$ & $0.84^{(1,2)}$ & $0.82^{(1,2)}$ & $0.96^{*}$ \\
\hline Profitability & $1.22^{(2,4)}$ & $1.57 *$ & $1.23^{(2,4)}$ & $1.66^{*}$ & $1.93 *$ \\
\hline
\end{tabular}

* indicates that population mean in the given quadrant is significantly different $(\mathrm{P}<0.01)$ to all other quadrants. Numbers in brackets indicates those quadrants with significantly different population means.

Table 3: Population averages of the efficiency-profitability matrix

\section{Discussion}

In the above case study for the Long Clears Forest portfolio we identified a class of logs, the "Super-stars", that demonstrated a high degree of efficiency and profitability in producing long clears in the bottom, pruned log. These logs had an average SED of $50 \mathrm{~cm}$, a large clearwood sheath, minimal sweep and moderate taper. We define these characteristics as being the optimal characteristics for the butt log of our designer tree intended to maximise profitability for clearwood production. Our primary conclusion from the efficiency-profitability model is, "the bigger the log and the straighter the log, the better the profitability".

The requirement for a large clearwood sheath can be met through pruning practices, perhaps in conjunction with longer rotations and lower stocking. While the size of the defect core can be readily manipulated through pruning, it was interesting to note that defect core size was not significantly different across quadrants in the efficiency-profitability matrix, in spite of the wide range of sites and silvicultural practices from which the modelled logs were derived. This suggests that the variability occurring in the size of defect cores does not have much impact on profitability. 
The Case Study for a Long Clears portfolio suggested that straightness (as well as size) was very important in improving profitability, both through increasing efficiency of processing and increasing product outturn. However, since only unimproved trees were modelled, and tree improvement has already led to a substantial improvement in straightness in all forests planted in New Zealand since 1884, it is not known how much profitability would be increased with additional selection for straightness over and above the current improved breeds. Repeating the Case Study using data from logs of improved trees would show how much additional selection for straightness would improve profitability. The exercise we carried out, however, does suggest that the improvements in straightness that have been achieved through tree breeding have resulted in substantial increased profitability. Furthermore, in the work presented here both efficiency and profitability were measured in terms of "green" products. Should the effects of drying distortion of lumber cut from swept logs be included, the flow on effects of log sweep may be even worse, and therefore, realised gains from tree improvement would be even higher than the case study indicates.

As mentioned earlier, we have only considered the butt log. However, defect-free material can be produced from the logs above the pruned butt log. Clearwood pieces can be obtained in the unpruned section between whorls and increased by manipulating internode length, which is amenable to selection and under moderate genetic control. The over-all goal for a Long Clear regime is to obtain as much of the desired product as possible from the entire tree, so we hope to extend the DEA model to the unpruned second log of the stem to generate yet further clearwood from the designer tree.

While we had a comprehensive database of pruned butt logs to apply in our DEA analysis presented here, our database of unpruned logs is more limited. Unlike the pruned log where all branches are encased within a zone known as the defect core, the unpruned second log has a much more complex structure. The presence of branches introduces a host of other complexities such as internodal lengths, number, location, orientation, and size of branches. We will aim to include important variables in the model such as internode index, mean internode length, and branch index of the second log.

Models for generating logs with branches and sinuous stems would be required to examine unpruned logs using a similar approach to the Case Study presented here. In addition, since internode length is negatively correlated with growth rate and with stem straightness, models that quantify these relationships are necessary. Unfortunately, these models do not yet exist. Branches on thousands of unpruned logs could be generated using the branch model BLOSSIM (Grace et al. 1999), but this model is designed to create branches, not logs. Sinuosity is not modelled, nor are the trade-offs quantified between increased internode length and increased 
sinuosity or between increased internode length and decreased growth rate. A better understanding and quantification of the interactions and relationships between internode length and straightness and internode length and growth rate are required in order to progress this work. One realistic approach to extending the Case Study to the second log would be to model second logs of only the "superstar" butt logs, and assume that the minimum value that would be accepted for straightness of second logs in the super star category would be high, and only consider these in the analysis. This does not take away the requirement that a better understanding of the relationships among straightness, internode length and growth, is necessary.

The method of weighting selection traits to maximise profitability commonly used in animal breeding and being promoted by many tree breeders (including Borralho et al. 1993, Chambers 1999, Greaves et al. 1997, Ponzoni 1986, Ponzoni and Newman, 1989) requires a model that is a linear combination of traits in which the coefficient of each trait is its effect on profit when all other traits are held constant (Hazel 1943). It would be possible to structure profitability models in this way, but is a mammoth task because of all the interactions among environmental, forest management, economic, and genetic factors which influence profitability. More importantly it ignores the extensive amount of well-tested and documented forest management models such as STANDPAK (Whiteside 1990) that have been shown to predict growth, product outturn, branching patterns, etc. The approach as defined by Hazel (1943) calculates breeding values based on profitability functions, which is an appropriate goal. However, in practice, application of this method has been limited to evaluation with the management variables set to their optimum value for that genotype (Goddard 1998). This is of limited utility because of the much larger effect of site and silviculture on performance as compared to the effect of genetic selection on performance, and because of the forest manager's requirement to consider a range of management options.

We suggest that Hazel's approach models profitability only indirectly and that other approaches using forest management models which take into account the impact of relevant site, silvicultural regime, and wood processing processes will give more realistic profit functions. An example of a better quantification of the amount of wood produced (which is very closely tied to profit) than could be achieved with this approach is prediction of genetic gain in growth with various levels of genetic improvement (Carson et al. 1999a). This approach builds upon existing well-tested growth models, and predicts volume with levels of genetic improvement for specific forest regions, site qualities and silvicultural regimes. The non-genetic factors included in the growth models have a much greater impact on the volume of wood produced than genetic improvement (Carson et al. 1999b). Growth models have been shown to predict accurately and have been developed over the years. It is unlikely that a model of the form proposed by Hazel 
(1943) will predict profitability with the same degree of accuracy as provided by the growth models.

The conclusions from the Case Study were drawn from considering the perspective of the endproduct and the solid-wood processor. Data Envelopment Analysis provided a framework for considering together both the efficiency of sawing and the volume of timber of the specified type (that is, long clears) given a specific sawing pattern. It appeared to provide a very realistic profitability function, which was useful for defining tree characteristics that maximise profitability.

This study has developed and explored the application of operational research tools, including data envelopment analysis, to define characteristics of an "optimal designer tree". Work with pruned butt logs suggest that the technique looks promising for defining the tree characteristics that optimise profitability of production of a specific end product, and quantifying the impact of changing relative economic weights on traits for genetic selection. However, a greater understanding of a vast range of complexities is required in order to extend the LongClear analysis to include the full stem.

\section{Acknowledgements}

The authors gratefully acknowledge the support and practical advice given by Mike Carson of Carson Associates Ltd. on many aspects of this study. 


\section{References}

Borralho NMG, Cotterill PP and Kanowski PJ (1993). Breeding objectives for pulp production of Eucalyptus globulus under different industrial cost structures. Canadian Journal of Forest Research 23: 648-656.

Boussofiane A, Dyson RG and Thanassoulis E (1991). Applied data envelopment analysis. European Journal of Operational Research, 52, 1-15.

Burdon RD (1992). Genetic survey of pinus radiata. 9: General discussion and implications for genetic management. New Zealand Journal of Forestry Science 22(2/3):274-98.

Carson SD (1996). Greater specialisation of improved seedlots: new developments for efficient selection of parents and evaluation of performance. NZ Forestry 41:12-17.

Carson SD, Garcia O and Hayes JD (1999a). Realised gain and prediction of yield with genetically improved Pinus radiata in New Zealand. Forest Science 45(2):186-200.

Carson SD, Kimberley MO, Hayes JD and Carson MJ (1999b). The effect of silviculture on genetic gain in growth of Pinus radiata at one-third rotation. Canadian Journal of Forestry Research 28(2):248-258.

Chambers P (1999). Radiata: an economic breeding objective. PhD Thesis. University of Tasmania, Hobart. 347 pp.

Charnes A, Cooper WW and Rhodes E (1978). Measuring the efficiency of decision making units. European Journal of Operational Research 2, 429-444.

Dyckhoff $\mathrm{H}$ and Allen K (2001). Measuring ecological efficiency with data envelopment analysis (DEA). European Journal of Operational Research, 312-325.

Ellis JC, Sanders DH and Pont D (1996). JAS log volume estimates of New Zealand radiata pine and Douglas-fir logs. N.Z. Forestry, May. Reprint 2595. 5pp.

Fotiou SI (2000). Efficiency measurement and logistics - an application of DEA in Greek sawmills in logistics in the forest sector, Kim Sjöström, Editor, publisher: Timber Logistics press: Hakapaino, Helsinki 2000, 295 pp., ISBN 952-91-1942-9. 
Goddard ME (1998). Consensus and debate in the definition of breeding objectives. Journal of Dairy Science 81: 6-18.

Grace JC, Pont D, Goulding CJ and Rawley B (1999). Modelling branch development for forest management. New Zealand Journal of Forestry Science 29(3): 391-408.

Greaves BL, Borralho NMG and Raymond CA (1997). Breeding objective for plantation eucalypts grown for production of kraft pulp. Forest Science 43: 465-475.

Oishi W (1998). XLP: Linear programming program for Windows. Kanto Tokai Journal of Farm Management. No. 89, p123 - 126. http://www.interq.or.jp/sun/ooisi/xlp e.html

Park JC and Leman CSE (1983). A sawing study method for evaluating timber from pruned logs. NZ Forest Service, Forest Research Institute, FRI Bulletin No. 47, 42pp.

Pont D, Grace J and Todoroki CL (1999). An analysis of the influence of branch characteristics on timber grade recovery. Proceedings of the Third Workshop IUFRO S5.01-04, France, pp 6371. Aug. Ed. G Nepveu, Publication Equipe de Recherches sur la Qualite des Bois, INRANancy, France.

Ponzoni RW (1986). A profit equation for the definition of the breeding objective of Australian merino sheep. Journal of Animal Breeding and Genetics 103:342-357.

Ponzoni RW and Newman S (1989). Developing breeding objectives for Australian beef cattle production. Animal Production 49:35-47.

Somerville A (1985). A field procedure for the cross-sectional analysis of a pruned radiata pine log. NZ Forest Service, FRI Bulletin No. 101.

Tian X and Cown DJ (1997). STANDQUA: A modelling tool to predict the interactions of site and silviculture on wood properties and $\log$ quality in New Zealand. Society of American Foresters, $7^{\text {th }}$ Symposium on Systems Analysis in Forest Resources, Traverse City, Michigan, May 1997. 8pp.

Todoroki CL (1990). Development of an automated sawing simulator. New Zealand Journal of Forestry Science 20:3, 332-348. 
Todoroki CL (1997a). Developments of the sawing simulation software, AUTOSAW: Linking wood properties, sawing, and lumber end-use. Proceedings of the Second Workshop, IUFRO S5.01-04, South Africa, August 26-31, 1996, 241-247, Ed. G Nepveu, Pubication Equipe de Recherches sur la Qualite des Bois, INRA-Nancy, France.

Todoroki CL (1997b). Primary and secondary log breakdown simulation. PhD Thesis. The University of Auckland, New Zealand.

Todoroki CL and Rönnqvist EM (1997). Secondary log breakdown optimization with dynamic programming. Journal of the Operational Research Society 48, 471-478.

Shelbourne CJA, Apiolaza LA, Jayawickrama KJS and Sorenson CT (1997). Developing breeding objectives for radiata pine in New Zealand. Proceedings of IUFRO '97 Genetics of Radiata Pine, Rotorua, New Zealand, 1-4 December, FRI Bulletin No. 203.

Whiteside ID (1990). STANDPAK modelling system for radiata pine. FRI Bulletin, Forest Research Institute, New Zealand. No. 51, 106-111. 